\title{
Literatura e REA: propostas metodológicas para educação literária aberta em cenários on-line de aprendizagem
}

\section{Literature and OER: Methodological Proposals for Open Literary Education in Online Learning Scenarios}

\author{
Eduardo Ferreira da Silva ${ }^{1 *}$, Maria Kaline de Lima Pedroza ${ }^{2}$, Ivanda Maria \\ Martins Silva ${ }^{3}$
}

\begin{abstract}
RESUMO
O objetivo principal deste trabalho é propor estratégias didático-metodológicas direcionadas ao ensino de literatura no nível médio, visando à formação de leitores críticos e autônomos no contexto da cultura digital, levando em conta as potencialidades dos Recursos Educacionais Abertos (REA). Como aporte teórico, foram priorizadas abordagens que discutem os REA no campo da educação aberta em cenários on-line de aprendizagem, bem como enfoques sobre educação literária na cultura digital. Em relação à metodologia adotada, trata-se de estudo exploratório/descritivo para mapeamento de plataformas digitais de Educação Aberta, visando à coleta de dados com foco em REA que pudessem ser explorados em propostas metodológicas para a educação literária aberta. Também investigamos como as diretrizes curriculares da BNCC propõem o ensino de literatura no contexto da cultura digital. Os resultados da pesquisa apontam para as potencialidades dos REA, em articulação com proposições didático-metodológicas para transformar positivamente a educação literária aberta.
\end{abstract}

Palavras-chave: Ensino de Literatura; Recursos Educacionais Abertos - REA; BNCC- Base Nacional Comum Curricular; Ensino Médio; Educação Literária Aberta.

\section{ABSTRACT}

This paper intens general to propose didactic-methodological strategies aimed at teaching literature at secondary level, aiming at the formation of critical and autonomous readers in the context of digital culture, taking into account the potential of Open Educational Resources (OER). As a theoretical contribution, approaches that discuss OER in the field of open education in online learning scenarios were prioritized, as well as approaches to literary education in digital culture. Regarding the adopted methodology, this is an exploratory/descriptive study for mapping digital platforms for Open Education, aiming at collecting data with a focus on OER that could be explored in methodological proposals for open literary education. We also investigate how the curricular guidelines of the BNCC propose the teaching of literature in the context of digital culture. The research results point to the potential of OER, in conjunction with didactic-methodological propositions to positively transform open literary education.

Keywords: Literature Teaching; Open Educational Resources - OER; BNCC- Common National Curriculum Base; High school; Open Literary Education.

\footnotetext{
${ }^{1}$ Universidade Federal Rural de Pernambuco (UFRPE/UEADTec). *E-mail: eduardoferreira092@gmail.com

${ }^{2}$ Universidade Federal Rural de Pernambuco (UFRPE/UEADTec)

${ }^{3}$ Universidade Federal Rural de Pernambuco (UFRPE/UEADTec/PPGTEG-PROGEL)
} 


\section{INTRODUÇÃO}

O ensino de literatura, especialmente no nível médio, encontra-se em discordância com as demandas do mundo globalizado e tecnológico no qual estamos inseridos. Basicamente, a literatura é tratada dentro da escola de maneira pouco produtiva, sendo reduzida a “[...] uma caricatura, na qual a leitura dos textos literários é substituída por listas de autores e características de estilo de época" (COSSON, 2014, p. 15).

Essa situação torna-se mais agravante porque os alunos de hoje cresceram cercados pelas Tecnologias Digitais de Informação e Comunicação (TDIC). Portanto, uma educação literária pautada numa perspectiva pouco significativa, que não contempla a leitura integral do texto e, pior ainda, que estigmatiza o vínculo do campo literário com as mídias digitais, em nada colabora para motivar os estudantes.

Pelo contrário, tal abordagem acaba distanciando-os da experiência leitora, pois esses “nativos digitais", denominados assim por Prensky (2001), vivenciam a cultura digital de forma intensa e naturalizada. Sendo assim, concebemos que não é aconselhável que o professor de literatura nutra algum tipo de preconceito em relação à presença das tecnologias no âmbito escolar, uma vez que o ensino de literatura pode se beneficiar nessa parceria - ou melhor, relação de simbiose - estabelecida com as TDIC.

Estando cada vez mais presentes nos ambientes virtuais do ciberespaço, leitores e autores estabelecem novos processos de interação com a literatura, por meio das mediações que as tecnologias propiciam. Considerando esse novo perfil de leitor, que agora também é “navegador", é imprescindível considerar as mídias digitais como recursos propícios à formação leitora, não competindo, de forma alguma, com a cultura do livro impresso. Ribeiro (2016, p. 112) corrobora esta ideia, ao apontar que "o livro digital, no entanto, não parece ter reduzido a força do livro impresso, tendo-o, ao contrário, como uma alternativa e mesmo um aliado".

Rouxel (2013) argumenta que ao se discutirem questões pertinentes ao ensino de literatura, é fundamental evidenciar a finalidade desse ensino: formar indivíduos livres, sensíveis, inteligentes, dotados de criticidade e, acima de tudo, capazes de recepcionar a obra com autonomia. Esse é o tipo de educação literária que devemos vislumbrar para os alunos, uma educação que ensine a ser livre e a pensar por conta própria, capaz de colocálos como protagonistas da própria aprendizagem (FREIRE, 2005).

O presente trabalho tem como objetivo geral propor estratégias didáticometodológicas direcionadas ao ensino de literatura no nível médio, visando à formação de 
leitores críticos e autônomos no contexto da cultura digital, levando em conta as potencialidades dos Recursos Educacionais Abertos (REA). A ênfase dada à Educação Aberta (EA) deve-se ao fato de ela propiciar, segundo Santaella (2014), uma aprendizagem que é altamente flexível e ubíqua, ocorrendo praticamente em quaisquer espaços e contextos, mediante a presença de recursos tecnológicos que propiciem interatividade.

Por sua vez, como questão norteadora da pesquisa, temos o seguinte questionamento: como repensar estratégias metodológicas para utilização de REA em educação literária aberta em cenários on-line de aprendizagem?

Como objetivos específicos da pesquisa, propomos: 1. Averiguar criticamente as orientações e diretrizes curriculares que constam na BNCC em relação ao ensino de literatura no nível médio; 2. Discutir características e potencialidades dos Recursos Educacionais Abertos (REA) para dinamizar o ensino de literatura em tempos de inovações tecnológicas; 3. Propor a adoção de alternativas didático-metodológicas com foco em REA para apoiar a educação literária aberta em meios digitais.

As motivações que levaram à escolha desse tema surgiram, em primeiro lugar, devido à hipótese levantada de que, em relação ao ensino de literatura no nível médio, ainda não há um número expressivo de estratégias metodológicas que dialoguem com os Recursos Educacionais Abertos (REA). Ou seja, eles ainda não são encarados ou utilizados pelos docentes como materiais didáticos, de fato (STAROBINAS, 2012).

Em segundo lugar, por estarmos cientes de que as práticas de leitura literária podem sair fortalecidas a partir da adoção dos REA em alternativas didático-metodológicas, levando em conta que os jovens são leitores/navegadores e, portanto, passam um tempo considerável no ciberespaço (local onde tais recursos estão preferencialmente disponíveis). Essa proximidade entre o aluno e a obra literária, intermediada pelos REA, teria a capacidade de fazê-lo encontrar prazer na leitura, afeiçoando-se a tal prática, não a enxergando como uma mera obrigação imposta pelo professor.

Em terceiro lugar, também teve como motivação a apreensão de que o ensino de literatura no nível médio deve estar em consonância com as orientações e diretrizes da Base Nacional Comum Curricular (BNCC), documento oficial e de caráter normativo que preconiza uma educação literária em sintonia com a cultura digital, com os diversos gêneros, linguagens e manifestações artísticas que dela emergem. Apesar das contribuições inovadoras da BNCC para com o campo artístico-literário, notam-se "lacunas" que serão discutidas de forma crítica.

Os resultados desta pesquisa poderão, teoricamente, evidenciar como os REA 
podem - em função de suas características e atributos - auxiliar o professor de literatura a proporcionar aos estudantes uma educação literária aberta, flexível e ubíqua.

\section{METODOLOGIA}

A metodologia será detalhada a seguir. O presente trabalho tem abordagem qualitativa pelo seguinte motivo: "a pesquisa qualitativa é uma atividade situada que posiciona o observador no mundo. Ela consiste em um conjunto de práticas interpretativas e materiais que tornam o mundo visível" (DENZIN; LINCOLN, 2006, p. 3 ) ao investigador, não exigindo que ele interprete dados estatísticos, lide com números, gráficos, etc.

Conforme Silva e Menezes (2001, p. 20), em uma pesquisa qualitativa a intersubjetividade do pesquisador é fundamental para a compreensão do objeto estudado e para a interpretação dos fenômenos, não requerendo "o uso de métodos e técnicas estatísticas", como ocorre na abordagem quantitativa. É o contato do pesquisador com o ambiente natural que lhe permitirá interpretar e atribuir significado aos fenômenos estudados.

O presente trabalho tem como objetivo geral propor estratégias didáticometodológicas direcionadas ao ensino de literatura no nível médio, visando à formação de leitores críticos e autônomos no contexto da cultura digital, levando em conta as potencialidades dos Recursos Educacionais Abertos (REA). Para tanto, realizamos pesquisa exploratória no ciberespaço para mapearmos plataformas de Educação Aberta, intencionado coletar Recursos Educacionais Abertos (REA) que pudessem ser articulados a estratégias didáticas para apoiar a educação literária aberta em meios digitais.

O referencial teórico desta pesquisa foi consolidado a partir de estudo bibliográfico e de pesquisa exploratória realizada na internet, onde mapeamos pesquisas já produzidas em sintonia com nosso objeto de estudo. Foram utilizados alguns portais, como: Scientific Electronic Library Online (SciELO), disponível em: 〈https://www.scielo.br/?ng=pt>, e a Biblioteca Digital de Teses e Dissertações (BDTD), disponível em: $<$ https://bdtd.ibict.br/vufind/>.

ENSINO DE LITERATURA E ORIENTAÇÕES CURRICULARES DA BNCC DO ENSINO MÉDIO 
Discutir sobre o ensino de literatura que vem sendo promovido pela maioria das escolas ao longo das últimas décadas é um tema que gera muitos questionamentos e demanda reflexões críticas. Especialmente pelo fato de que a literatura e as práticas de leitura literária são colocadas de lado em detrimento de uma abordagem anacrônica, pouco eficaz para contribuir na formação do leitor. Como enfatiza Cosson (2006, p. 34), "aceitar a existência do cânone como herança cultural que precisa ser trabalhada não implica prender-se ao passado em uma atitude sacralizadora das obras literárias".

Esse "apagamento" da literatura na sala de aula é preocupante porque a retira do lugar de centralidade que ela deveria ocupar no ensino de língua materna (DALVI, 2013). Além disso, também se configura como uma perda substancial à formação humana, pois “[...] se a presença da literatura é apagada da escola, se o texto literário não tem mais lugar na sala de aula, desaparecerá também o espaço da literatura como lócus de conhecimento" (COSSON, 2014, p. 15). Dessa forma, o aluno acaba sendo privado de uma formação integral que só o contato direto com a obra literária poderia proporcionar.

Validando esta ideia, Dalvi (2013, p. 78) aponta que "o texto literário não deve ser considerado como uma área apendicular [...] da disciplina de português", mas sim "como a manifestação da memória criativa da língua portuguesa". Isso significa que tratar "a obra literária como conteúdo semelhante a outras disciplinas, não faltando a prova, o resumo e outras formas de forçar a leitura [...] é introjetar no aluno uma imagem desabonadora da literatura" (COSSON, 2014, p. 14), destituindo-a de sua potencialidade formativa e, principalmente, humanizadora.

Todorov (2009) chama de "literatura reduzida ao absurdo" essa forma enrijecida e estéril como a arte literária é ensinada, visto que o aluno não é levado a ler e entender por si próprio aquilo que leu. Antes que isso aconteça já lhe são apresentadas explicações previamente prontas e que não prescindem do mínimo esforço cognitivo de sua parte, já que todas as informações que o estudante teoricamente precisaria saber são fornecidas pela crítica e veiculadas pelo professor de literatura (apoiados pelo livro didático). Desse modo, apreendemos que os discentes não têm contato com a obra literária em si (impossibilitando, assim, as diversas interpretações que surgiriam dessa recepção), mas apenas com o juízo de valor que a crítica especializada faz dela. A respeito dessa questão, o autor esclarece que:

Os estudos literários têm como objetivo primeiro o de nos fazer conhecer os instrumentos dos quais se servem. Ler poemas e romances não conduz à reflexão sobre a condição humana, sobre o indivíduo e a sociedade, o amor e o ódio, a alegria e o desespero, mas sobre as noções críticas, 
tradicionais ou modernas. Na escola, não aprendemos acerca do que falam as obras, mas sim do que falam os críticos. (TODOROV, 2009, p. 27).

Ao tecer estes comentários, não estamos desqualificando as interpretações e avaliações feitas pela crítica literária acerca das obras que julgam. Pelo contrário, assim como Colomer (2007), também partilhamos da ideia de que a "crítica valorativa" a respeito de uma determinada obra deve ser feita somente após sua leitura, quando a construção pessoal do sentido já tem ocorrido. Em outras palavras, "quando o efeito e a compreensão da leitura foram alcançados, os leitores gostam de conhecer as interpretações que outros leitores especializados fizeram" (COLOMER, 2007, p. 183).

Após nos aprofundarmos sobre a importância da literatura para a formação integral do ser humano e refletirmos acerca da necessidade de que seu ensino não se paute apenas numa abordagem historicista e biográfica, iremos agora discutir as diretrizes da Base Nacional Comum Curricular (BNCC) do Ensino Médio (BRASIL, 2018) em relação ao que deve ser ensinado no campo artístico-literário. Sendo um documento oficial, de caráter regulador e normativo, cuja responsabilidade é orientar a elaboração dos currículos das escolas de todo o país, é pertinente lançarmos um olhar crítico sobre ele.

Com a BNCC tendo sido aprovada e homologada em dezembro de 2018, podemos enfatizar que o seu processo de elaboração foi palco de importantes disputas e embates, tendo em vista que a constituição de um documento dessa magnitude não ocorreria de forma passiva e "unilateral", ou seja, sem haver qualquer conflito e envolvendo apenas os atores da educação (professores, gestores, comunidade escolar, etc), já que quando se trata de educação, interesses divergentes - de cunho social, político e ideológico - são mobilizados e colocados em polaridades distintas.

Atentando-nos para as orientações e diretrizes curriculares da BNCC em relação ao campo artístico-literário, percebemos que há, em sua redação, uma nítida preocupação em se atender às necessidades e demandas da cultura digital; buscando, então, estar em consonância com uma sociedade altamente tecnológica e informatizada. Para tanto, o texto do documento defende a sustentação de um ensino de língua portuguesa/literatura pautado nas “práticas contemporâneas de linguagem”, com relevância para

a cultura digital, culturas juvenis, os novos letramentos e os multiletramentos, os processos colaborativos, as interações e as atividades que têm lugar nas mídias e redes sociais, os processos de circulação de informações e a hibridização dos papéis nesse contexto (de leitor / autor e produtor / consumidor). (BRASIL, 2018, p. 490). 
Em busca dessa sintonia com a cultura digital, apreendemos que um dos aspectos mais centrais da BNCC é a preocupação que seu texto demonstra em relação ao jovem ser proficiente no uso das tecnologias e mídias digitais, levando em conta que elas são, no contexto atual, responsáveis por intermediar os processos interacionais, de aprendizagem e até mesmo de leitura literária. Essa preocupação é justificada pelo fato de que "a tecnologia é a sociedade, e a sociedade não pode ser entendida ou representada sem suas ferramentas tecnológicas" (CASTELLS, 1999, p. 43). Em relação a esse assunto, o documento aponta que

propostas de trabalho que possibilitem aos estudantes o acesso a saberes sobre o mundo digital e a práticas da cultura digital devem também ser priorizadas, já que impactam seu dia a dia nos vários campos de atuação social. Sua utilização na escola não só possibilita maior apropriação técnica e crítica desses recursos, como também é determinante para uma aprendizagem significativa e autônoma pelos estudantes. (BRASIL, 2018, p. 478).

Atentos ao fato de que as práticas de leitura foram ressignificadas pela difusão e expansão das mídias digitais, notamos que a BNCC busca consolidar um ensino de literatura que contemple a intersecção desse campo com múltiplos suportes e linguagens. Ou seja, segundo as diretrizes da BNCC, a literatura deve se fazer presente na sala de aula de formas diversas, vinculada a gêneros híbridos e multissemióticos, como produções cinematográficas, peças teatrais, canções, vlogs, podcasts, etc.

Para encontrar modos de experimentar e posicionar-se, os estudantes podem participar de eventos e práticas artísticas coletivas, mediante sua própria produção artística, combinando a escrita literária com outras formas semióticas de expressão. Desse modo, eles podem expor suas preferências ideológicas e estéticas e consolidar um conjunto de valores e conhecimento da língua e da arte. (BRASIL, 2018, p. 513).

Isso não significa, de forma alguma, que a obra escrita tenha perdido sua importância e relevância para a formação do leitor. Ao ser veiculado por meio de diferentes gêneros, expressões artísticas e linguagens multissemióticas (filmes, vlogs, podcasts, etc.), tendo como suporte os dispositivos eletrônicos, o texto literário acaba sendo ressignificado e adentra muitos espaços, atingindo públicos heterogêneos, podendo servir, eventualmente, como "porta de entrada" à leitura literária. 
Em contrapartida, apesar do importante diálogo que o campo artístico-literário estabelece com a cultura digital, não constatamos, no texto da BNCC, nenhuma diretriz clara a respeito de como se deve proceder em relação à leitura integral de obras literárias na escola, com a fruição que só a experiência com o texto pode proporcionar ao aluno. Faltam orientações curriculares claras e objetivas sobre como os educadores podem proceder na prática, no cotidiano escolar (IPIRANGA, 2019).

Ao analisarmos criticamente as habilidades (EM13LP52) e (EM13LP53), constatamos o que foi dito anteriormente: não há orientações sobre como promover a leitura integral do texto literário na sala de aula, em como permitir o contato direto do aluno com a obra, sendo a literatura, portanto, ressignificada por meio de outras práticas e linguagens que prescindem quase que totalmente de suportes tecnológicos.

(EM13LP52) Produzir apresentações e comentários apreciativos e críticos sobre livros, filmes, discos, canções, espetáculos de teatro e dança, exposições etc. (resenhas, vlogs e podcasts literários e artísticos, playlists comentadas, fanzines, e-zines etc.) (Competências específicas 1,3) (BRASIL, 2018, p. 516).

(EM13LP53) Criar obras autorais, em diferentes gêneros e mídias mediante seleção e apropriação de recursos textuais e expressivos do repertório artístico -, e/ou produções derivadas (paródias, estilizações, fanfics, fanclipes etc.), como forma de dialogar crítica e/ou subjetivamente com o texto literário (Competências específicas 1,3) (BRASIL, 2018, p. 516).

Outra ressalva importante a ser feita é a questão de não haver, no documento, qualquer menção ou orientação explícita para o ensino de literatura vinculado aos Recursos Educacionais Abertos (REA), não levando em conta as vantagens que eles têm a oferecer: o fato de serem gratuitos, usarem licenças de direitos autorais menos restritivas, poderem ser remixados e compartilhados livremente, etc. Sem dúvida alguma, ao não se atentar para o potencial dos REA para apoiar a educação literária aberta em cenários on-line de aprendizagem, a BNCC se mostra parcialmente limitada no diálogo que tenta manter com a cultura digital.

\section{CARACTERÍSTICAS E POTENCIALIDADES DOS REA PARA DINAMIZAR O ENSINO DE LITERATURA}


A educação é um direito essencial e inalienável de todo e qualquer cidadão, devendo ser ofertada, segundo Cury (2002), de forma gratuita e igualitária a todos pelo Estado. Entretanto, na prática, as coisas não funcionam exatamente assim, pois há vários fatores que corroboram para manter os alunos longe da sala de aula: de ordem financeira, distância geográfica da escola, dentre outros.

Pensando em tais empecilhos que se interpõem entre os jovens e o acesso a uma educação de qualidade, intencionando superá-los, Amiel (2012) aponta para o movimento da Educação Aberta (EA) como alternativa potencialmente capaz de alcançar esse objetivo. Esse modelo de educação é pautado na flexibilidade e na democracia, pois, nele, a aprendizagem pode ocorrer em diversos espaços e a qualquer momento, não ficando a aprendizagem restrita apenas ao espaço físico da escola; tendo o aluno acesso livre a conteúdos e materiais didáticos sem nenhum custo financeiro, precisando ter apenas algum dispositivo eletrônico em mãos.

Por ser uma modalidade essencialmente ubíqua e democrática, é nítido que a Educação Aberta tem por objetivo principal:

Fomentar (ou ter a disposição) por meio de práticas, recursos e ambientes abertos, variadas configurações de ensino e aprendizagem, mesmo quando aparentam redundância, reconhecendo a pluralidade de contextos e as possibilidades educacionais para o aprendizado ao longo da vida. (AMIEL, 2012, p. 19).

Diante das inúmeras possibilidades que a EA oferece às práticas educativas formais e informais, apontamos que é possível tirar proveito de todo esse potencial a partir da adoção de propostas metodológicas que estabeleçam diálogo entre a educação literária aberta com a cultura digital. É imprescindível repensarmos o ensino de literatura tradicional, focado apenas em abordagens anacrônicas e dissociadas das reais demandas dos jovens, buscando, para isso, novos percursos de aprendizagem.

Como já foi amplamente discutido anteriormente, reforçamos que o ensino de literatura no nível médio não pode se resumir ao historicismo e biografismo literário, pois tal abordagem é frágil e limitada ao ter "como ponto de partida não o texto, mas informações históricas, formais, sobre autores e obras" (ALVES, 2013, p. 45), não sendo capaz de atrair o jovem. Como defende Zilberman (2008, p. 16), "não se trata de rejeitar o caminho percorrido, mas de ajustá-lo aos novos tempos, pois a história não pára” e não podemos ficar presos a métodos ou práticas datadas. 
Apesar de ainda haver a persistência de uma educação literária que prioriza em demasia fatos históricos, também assumimos que as práticas de leitura e os modos de se consumir a literatura modificaram-se bastante com a emergência das mídias digitais. "Agora, os tempos mudaram, o avanço tecnológico proporciona computadores, tablets, celulares e outros recursos que têm reinventado a leitura e mudado as formas do leitor agir sobre o texto" (COSCARELLI; CAFIERO, 2013, p. 10).

Cientes da necessidade de se redefinir e adequar o ensino de literatura às demandas dos estudantes do nível médio, iremos discutir e propor alternativas didático-metodológicas capazes de alcançar esse objetivo, ancorando-nos numa abordagem de educação literária aberta, flexível e ubíqua. Estando cada vez mais presentes nos ambientes virtuais do ciberespaço, os "[...] autores e leitores assumem papéis ainda mais dinâmicos, diante da interatividade dos meios eletrônicos" (MARTINS, 2006, p. 97). Não podemos, de forma alguma, ignorar essa mudança na relação entre texto, autor e leitor.

Dalvi (2013) traz algumas sugestões teórico-metodológicas bastante pertinentes sobre como proceder com o ensino de literatura no contexto escolar. Iremos embasar as reflexões em torno dessas propostas, articulando-as a uma concepção de educação literária aberta, centrada na ubiquidade e flexibilidade, passível de ocorrer tanto em ambientes formais quanto informais.

Quando trata de "alguns princípios para o trabalho com a literatura na escola", a autora aponta, nesses tópicos, para a importância de se:

(d) Reconhecer que a mudança de suportes e de modos de apresentação implica alteração recepcional (portanto, não basta trazer o texto "em si mesmo"): é preciso trazer o livro, o tablet, a cópia, o outdoor, a gravação, a declamação, o cartaz etc. e conversar sobre os impactos que são perceptíveis. (DALVI, 2013, p. 82).

(f) Instituir a pesquisa e o conhecimento como inerentes à atividade de leitura literária (para ler um texto é necessário saber sobre ele, seu autor, seu suporte, seus contextos, seus mecanismos, seus diálogos intertextuais, suas alusões à história). (DALVI, 2013, p. 82).

(p) Fazer da leitura literária uma sedução, um desafio, um prazer, uma conquista, um hábito: para isso, incorporá-la ao cotidiano escolar (e extraescolar) de todos (e talvez principalmente do próprio professor, como leitor em evidência). (DALVI, 2013, p. 84).

Percebemos, nitidamente, que tais tópicos se alinham a uma proposta de educação literária aberta, pois reconhecem que os modos como um texto é apresentado ao aluno, considerando também seu suporte, interferem na maneira que ele o recepciona. Levando em 
conta que a maioria dos leitores de hoje tem contato com a literatura ao navegar em ambientes virtuais do ciberespaço, é imprescindível que o professor, ao estruturar suas propostas didático-metodológicas, pense em refletir com a turma como ela enxerga o ensino de literatura em cenários on-line de aprendizagem, discutindo quais as diferenças da abordagem tradicional (centrada na aula expositiva, no uso do livro didático) para essa mais arrojada, que dialoga com a cibercultura.

Analisando os tópicos (f) e (p), podemos averiguar que tais propostas convergem para um trabalho em que a preocupação incide sobre o texto literário em si, em entender seu contexto (histórico, autoral e intertextual), para que, assim, seja possível compreendê-lo com propriedade. Incorporar a leitura literária ao contexto escolar e extraescolar, conforme defende Dalvi (2013), mostra-se em total sintonia com a principal diretriz da Educação Aberta: a ubiquidade. Ou seja, a literatura torna-se potencialmente mais atrativa porque não fica restrita apenas aos muros da escola, com horários fixos e estipulados, dando oportunidade ao leitor de apreciá-la quando lhe for oportuno. No tocante à "avaliação do trabalho com a literatura na escola”, Dalvi (2013) orienta que é preciso:

(c) Familiarizar os leitores em formação com todos os gêneros (poema lírico, poema narrativo, carta, bilhete, peça, esquete, piada, provérbio, tirinha, poema visual, narrativa curta, narrativa longa), suportes e modos de apresentação (visual, verbal, fílmica, musical, escrita, oral) do texto literário que forem possíveis - como parte inerente a esse trabalho, é necessário discutir tudo isso (a linguagem, o gênero, o suporte, o modo de apresentação, o estilo) com a equipe escolar e com os estudantes. (DALVI, 2013, p. 82 ).

Em concordância com a autora, também julgamos que é de extrema relevância que o aluno esteja habituado aos diversos gêneros, linguagens e suportes nos quais a literatura se manifesta (dos mais simples e corriqueiros aos mais complexos e sofisticados). Martins (2014) também respalda essa ideia, ao esclarecer que:

No cenário dinâmico das inovações tecnológicas, a literatura busca adaptar-se e encontra novos caminhos, seja nas transformações dos gêneros literários diante dos novos suportes, seja nas relações entre autores-textos-leitores agora mediadas pelas mídias digitais. Leitores e autores deparam-se com hiperficção, ciberpoemas, fotopoesia, poesia digital, fanfics, blogs literários, além de uma série de novos espaços hipermidiáticos e discursivos para práticas de letramento literário. (MARTINS, 2014, p. 71).

As ponderações feitas em torno das sugestões didático-metodológicas de Dalvi (2013) tiveram como intuito apenas esboçar que existem formas diversas para o docente 
trabalhar com a educação literária aberta em cenários digitais, não tendo intencionado, de forma alguma, promover uma discussão longa e exaustiva do assunto.

Já esclarecemos e conceituamos o que é o movimento pela Educação Aberta, em que flexibilidade e ubiquidade são termos imperativos. A partir de agora, iremos abordar o que são os Recursos Educacionais Abertos (REA), refletindo acerca de suas características e potencialidades para democratizar e dinamizar a educação literária aberta.

Em seu documento, a Unesco/Commonwealth of Learning, em 2011, define os REA como:

Materiais de ensino, aprendizado, e pesquisa em qualquer suporte ou mídia, que estão sob domínio público, ou então estão licenciados de maneira aberta, permitindo que sejam utilizados ou adaptados por terceiros. $\mathrm{O}$ uso de formatos técnicos abertos facilita o acesso e o reuso potencial dos recursos publicados digitalmente. Recursos educacionais abertos podem incluir cursos completos, partes de cursos, módulos, livros didáticos, artigos de pesquisa, vídeos, testes, software, e qualquer outra ferramenta, material ou técnica que possa apoiar o acesso ao conhecimento. (UNESCO, 2011, p. V).

Tal definição já nos evidencia a natureza e o propósito dos REA: fazer com que materiais sejam produzidos e disponibilizados livremente ao público. O objetivo da cultura REA é justamente fazer com que esses recursos possam ser usados, remixados e adaptados conforme as necessidades dos diferentes usuários que deles se utilizarão, sem custo financeiro algum. A respeito da intrínseca relação entre Educação Aberta e REA, Amiel (2012) defende que

\footnotetext{
o acesso aos recursos educacionais é essencial para o desenvolvimento de configurações mais flexíveis de ensino e aprendizado. Recursos educacionais abertos não fazem somente parte dessa expansão, mas são verdadeiramente propulsores de novas configurações de ensino e aprendizagem. (AMIEL, 2012, p. 24).
}

Pensando nas diversas possibilidades que os REA oferecem às práticas educativas, nosso intuito é justamente tirar proveito deles para apoiar e enriquecer a educação literária aberta que ocorre mediante cenários on-line de aprendizagem, encarando o desafio que é formar o jovem leitor que vive hiperconectado ao ciberespaço.

Com o objetivo claro de fazer link entre os REA e a educação literária na cultura digital, fizemos uma busca mais abrangente no Google investigando sobre portais REA: onde seria possível encontrar esse tipo de material, quais as licenças que tais artefatos possuíam e se havia algo relativo à literatura. Eis que encontramos dois portais que se 
mostraram bastante promissores: o REliA, disponível em: 〈https://relia.org.br/>; e o Apps Univesp - Repositório da Universidade Virtual do Estado de São Paulo, disponível em: $<$ https://apps.univesp.br/repositorio/>.

A análise dos referidos portais (REliA e Apps Univesp) nos fez concluir que, apesar de a produção de REA ainda ser tímida, especialmente aquela voltada para a literatura, eles possuem significativo potencial para apoiar e dinamizar a educação literária aberta, pois se mostram como recursos que atraem o aluno, despertam seu interesse. Contudo, ressaltamos que apenas a utilização de REA por si só não garante mudanças de paradigmas no ensino de literatura, pois tudo depende da postura pedagógica do professor e de como ele utilizará os recursos educacionais na prática.

Na próxima subseção, discutiremos sobre os REA e como eles podem apoiar a educação literária aberta a partir da conexão com estratégias metodológicas.

\section{REA: CONEXÃO COM PROPOSTAS METODOLÓGICAS PARA APOIAR A EDUCAÇÃO LITERÁRIA ABERTA}

Os REA possuem um amplo potencial de fomentar as práticas envolvendo a educação literária aberta, como bem já foi discutido. Em nome dessa inerente potencialidade, eles podem (e devem) ser utilizados em propostas didático-metodológicas para enriquecer o trabalho do professor de literatura, tanto dentro quanto fora do contexto escolar.

Como assinala Starobinas (2012, p.123), os recursos abertos se diferenciam porque "rompem com uma tradição de propriedade, na qual [...] é proibida a utilização e adaptação de qualquer material produzido por outrem sem expressa autorização de seus detentores de direitos autorais”. Dessa forma, os professores podem se valer dos REA na elaboração de suas propostas didáticas sem temer estar infringindo a lei dos direitos autorais. Com isso, eles acabam contando com uma gama diversificada de recursos disponíveis na internet (em sites, repositórios, plataformas, etc) para além do corriqueiro e sempre presente livro didático. Este último nem sempre é um bom ajudante na formação do leitor literário, pois, muitas vezes, "o livro didático exclui a interpretação e, com isso, exila o leitor" (ZILBERMAN, 2009, p. 35).

Pensando em alternativas metodológicas arrojadas direcionadas aos professores de literatura e que estejam articuladas aos REA, podemos nos apoiar em uma proposta de 
Cosson (2020, p. 187), centrada naquilo que o autor chama de leitura responsiva, que pode ser definida como: o "registro do encontro entre leitor e a obra literária em um outro texto". A obra que serviria de base para tal proposta é uma pertencente ao escritor realista Machado de Assis, disponível no Portal Domínio Público.

Dispondo o referido portal de um vasto número de obras machadianas (e de outros escritores brasileiros e estrangeiros, como José de Alencar, Gonçalves Dias, Júlio Verne) o professor poderia, por exemplo, selecionar o sucinto conto "A Cartomante", disponível em:

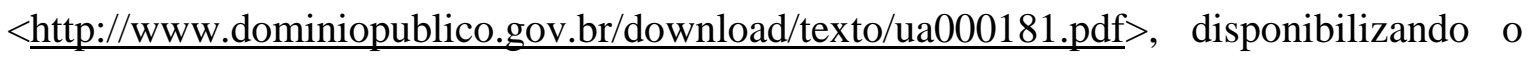
texto para todos os alunos (por e-mail, WhatsApp ou por outra rede social/mensageiro que julgar mais adequado) e promover uma leitura coletiva durante a aula. Em seguida, o educador discutiria com os alunos o que eles apreenderam do conto, extraindo as múltiplas interpretações que emergiram e enriqueceram o entendimento do coletivo. A partir da apropriação do texto em pauta, o professor solicitaria uma atividade que demandaria muita criatividade e interação com a obra literária: a criação de fanfictions (COSSON, 2014).

Basicamente, essa escolha pode ser justificada pelo caráter democrático que envolve a criação das fanfictions, possibilitando que o aluno assuma, digamos assim, o papel de coautor do texto que consome e se apropria. O professor orientaria que os estudantes formassem duplas e reescrevessem o conto usando a máxima da criatividade, para que o resultado final não fosse apenas "uma mera paráfrase do texto original" (COSSON, 2014, p. 12), totalmente em desacordo com a premissa do que é um fandom, de fato.

Posteriormente, após a escrita (e devidas correções) dessas fanfictions, a dupla decidiria, de comum acordo, onde a produção seria publicada (em blogs, redes sociais, sites), dispondo de variados suportes e ferramentas para diferenciar seus trabalhos. Ou seja, os alunos seriam incentivados a gravar podcasts (oralizando o que produziram), vídeos (resenhando o texto original com suas fanfics) e a disponibilizar esse conteúdo no Youtube, Spotify, Instagram, repositórios de REA, etc.

O objetivo maior deste trabalho seria possibilitar que o aluno fosse conquistado pelo texto literário e, com isso, "permitir a experiência de ensaiar escrever/produzir literatura, como resposta amorosa ao ato de ler" (DALVI, 2013, p. 82). Teoricamente, a turma estaria engajada com tal proposta metodológica não por imposição do docente, mas sim pela afetividade com a leitura e a liberdade de recriar a obra de forma criativa, usando as mídias digitais que lhe são tão caras e familiares.

Além disso, esse material produzido pelos estudantes poderia (depois de ter sido feita a devida curadoria pelo professor, é claro) servir como REA. Ou seja, a partir do 
momento em que esses recursos abertos fossem disponibilizados na rede, outros educadores e alunos poderiam se servir deles e, ao mesmo tempo, enriquecê-los: remixando-os, adaptando-os a seus contextos e interesses e, o mais importante, sem esquecer-se de compartilhá-los depois na internet para que o ciclo de utilização dos REA seja cumprido.

Essa proposta delineada foi apenas um mero esboço de como o professor pode tornar o contato do aluno com a literatura em algo prazeroso e significativo para sua aprendizagem, em consonância com uma educação literária aberta que se concretiza não apenas no espaço circunscrito da sala de aula, mas também fora dela, nas infovias do ciberespaço. Sem nenhuma imposição de horário ou regra rigidamente preestabelecida, ou seja, de acordo com os preceitos de uma aprendizagem ubíqua e altamente flexível (SANTAELLA, 2014).

\section{ANÁliSE DE PORTAIS DE EDUCAÇÃO ABERTA: CONEXÕES COM PROPOSTAS METODOLÓGICAS PARA A EDUCAÇÃO LITERÁRIA ABERTA}

Portais que oferecem Recursos Educacionais Abertos (REA) permitem que os professores tenham à sua disposição materiais gratuitos e diversificados que podem enriquecer e dinamizar suas propostas metodológicas para a promoção de uma educação literária aberta.

Tendo em vista que os REA são altamente plásticos, podendo ser adaptados conforme os interesses e objetivos de cada professor para atender às necessidades de seu público-alvo, vamos analisar de forma geral os seguintes portais: REliA, disponível em: <https://relia.org.br/>; e APPS UNIVESP - Repositório da Universidade Virtual de São Paulo, disponível em: 〈https://apps.univesp.br/repositorio/>, nos detendo aos recursos e materiais que eles disponibilizam que possam apoiar o ensino de literatura em cenários online de aprendizagem. Vamos começar pelo REliA. 
Figura 1 - Página inicial da plataforma REliA

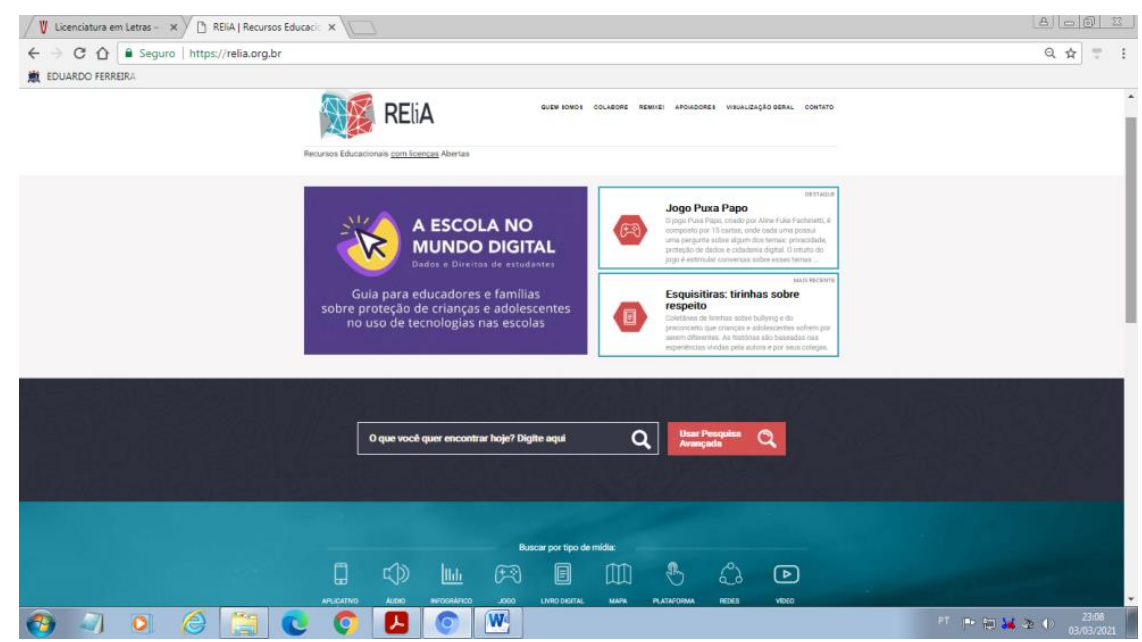

Fonte: <https://relia.org.br/>. Acesso em: 03 mar. 2021

Basicamente, o REliA é um ambiente que reúne uma série de materiais (como textos, vídeos, podcasts, jogos, entre outros) separados de acordo com a área de conhecimento/disciplina a que pertencem e licenças de uso que possuem. Como consta na própria descrição da plataforma, o potencial dos REA para enriquecer ou não o processo de ensino-aprendizagem dos alunos vai depender da proposta pedagógica de cada professor, pois somente ele é capaz de julgar criteriosamente o que seu público-alvo precisa.

Como o nosso foco são recursos que auxiliem a educação literária aberta, digitamos a palavra "literatura" na caixa de busca e apareceram 5 resultados, dos quais os três últimos já foram descartados logo de cara: o podcast Gêneros Textuais - Definições e Funcionalidades (por não abordar nenhum tópico referente à literatura); o livro digital The Divine Comedy, IIlustrated by Dante Alighieri (por estar totalmente em inglês) e a página da SmartHistory (que consta como inexistente).

Levando em conta apenas os recursos que sobraram e que são viáveis para o trabalho com a literatura, apuramos que as duas opções restantes direcionam para portais/sites que disponibilizam livros digitais que estão sob domínio público (como vários de Fernando Pessoa e a obra "A Moreninha”, de Casimiro de Abreu, respectivamente). 
Figura 2 - Obras de Fernando Pessoa, disponíveis no Portal Domínio Público

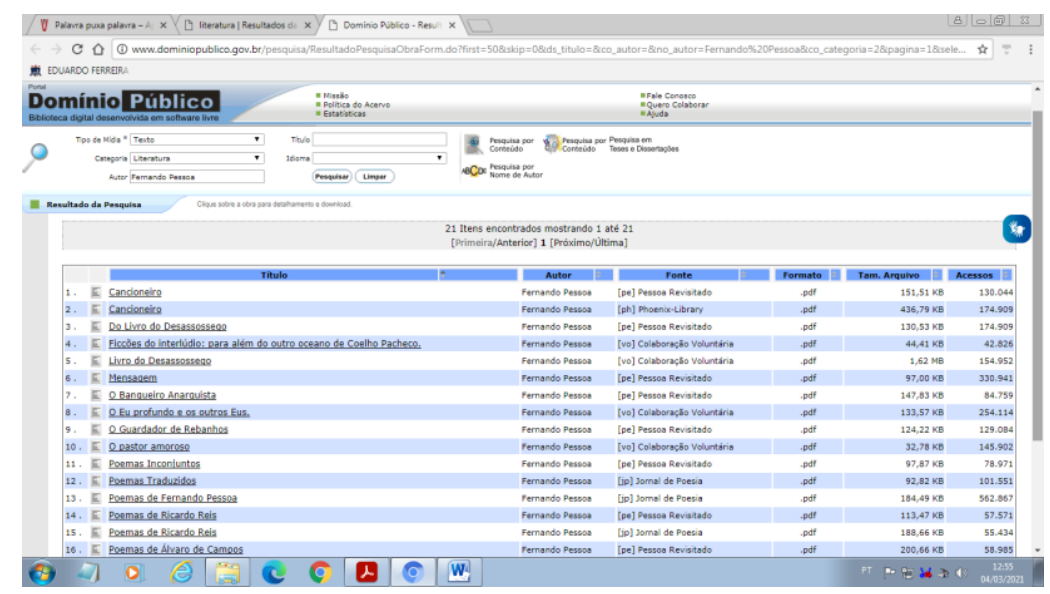

Fonte:

<http://www.dominiopublico.gov.br/pesquisa/ResultadoPesquisaObraForm.do?first=50\&s kip $=0 \& d s \_t i t u l o=\& c o \_a u t o r=\& n o \_a u t o r=F e r n a n d o \% 20 P e s s o a \& c o \_c a t e g o r i a=2 \&$ pagina $=$ $1 \&$ select_action $=$ Submit $\&$ co_midia $=2 \&$ co_obra $=\& c o \_i d i o m a=\&$ colunaOrdenar $=D S \_T I T$ ULO\&ordem=nu. Acesso em: 04 mar. 2021

Figura 3 - Livro digital "A Moreninha”, disponível gratuitamente na Amazon

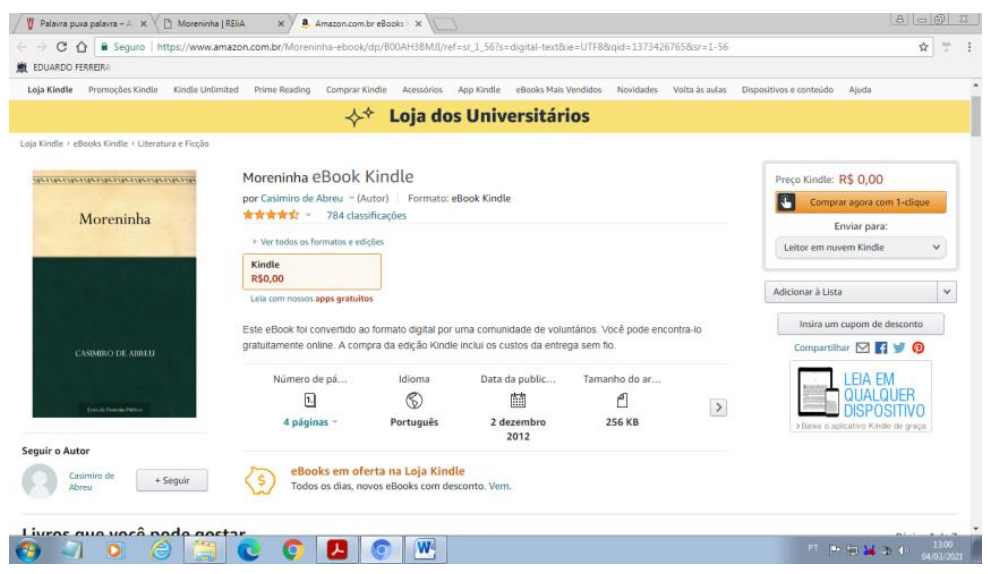

Fonte: <https://www.amazon.com.br/Moreninhaebook/dp/B00AH3BMJI/ref=sr_1_56?s=digital-text\&ie=UTF8\&qid=1373426765\&sr=156>. Acesso em: 04 mar. 2021.

Apreendemos que apesar de a plataforma REliA não contar com uma enorme gama de REA para apoiar a educação literária aberta, o professor ainda sim pode contar com um número expressivo de obras para dinamizar sua prática educativa, podendo utilizar os livros digitais para promover a leitura em si (que é algo imprescindível) e como matéria-prima para os alunos produzirem vídeos, podcasts, blogs, resenhas, fanfics, etc. 
Por sua vez, fazendo agora uma breve descrição do APPS UNIVESP - Repositório da Universidade Virtual de São Paulo, disponível em: <https://apps.univesp.br/repositorio/>, vemos que os conteúdos são organizados por categorias. Ao clicarmos na categoria "Licenciatura em Letras", obtivemos 3 resultados. Entretanto, apesar desse resultado, esclarecemos que nos interessa analisar apenas o REA "Foco Narrativo", disponível em: < https://apps.univesp.br/foco-narrativo/>, pois é o único que realmente aborda um tema pertinente ao campo literário.

Figura 4 - REA encontrados na categoria "Licenciatura em Letras"

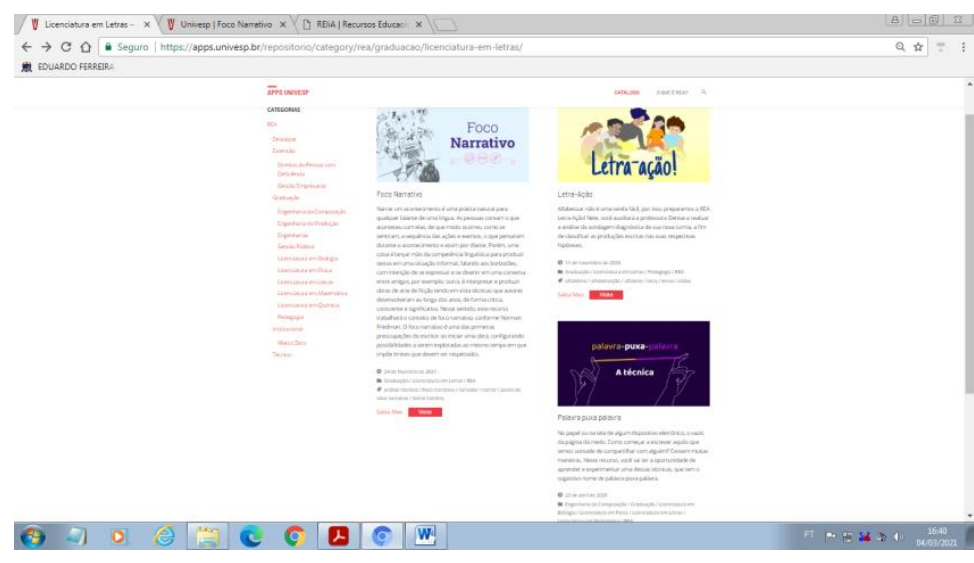

Fonte: <https://apps.univesp.br/repositorio/category/rea/graduacao/licenciatura-emletras/>. Acesso em: 04 mar. 2021

Figura 5 - Página inicial do REA "Foco Narrativo"

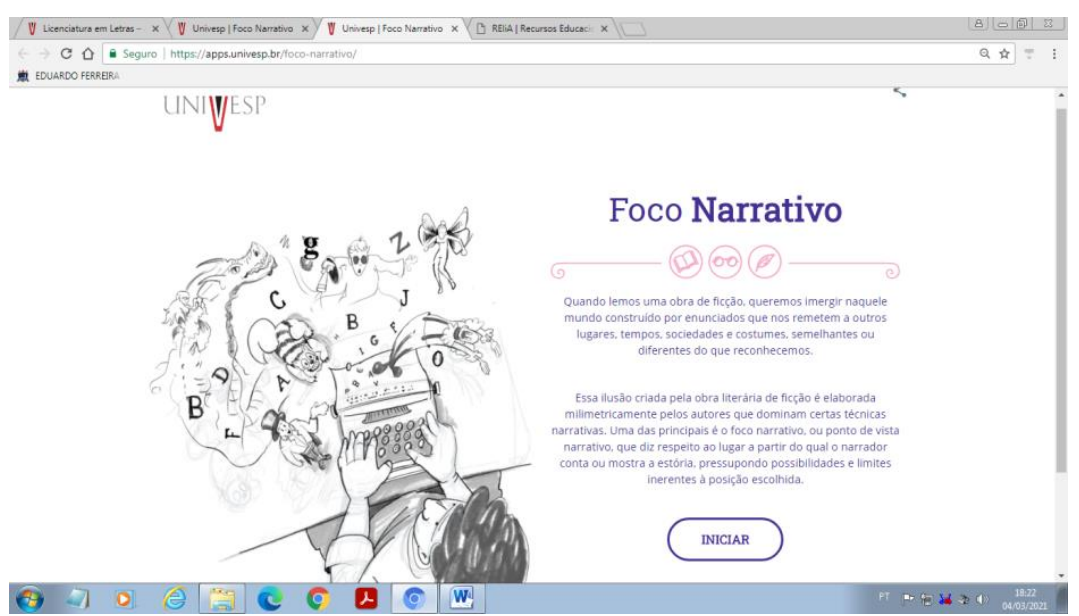

Fonte: <https://apps.univesp.br/foco-narrativo/>. Acesso em: 04 mar. 2021 
De modo geral, este REA tem uma proposta didática bem interessante, pois une a dinâmica de trazer informações e logo em seguida fazer uma série de perguntas acerca do assunto, como uma espécie de quiz para que o usuário teste seus conhecimentos, verificando se realmente assimilou o conteúdo. É um recurso rico e cheio de potencial para apoiar o ensino de literatura em ambientes virtuais.

Feitas tais considerações, só nos resta novamente pontuar como os REA podem tornar o ensino de literatura mais significativo e dinâmico, em sintonia com esses tempos nos quais predominam as inovações tecnológicas. Como bem pontua Rojo (2017, p. 7), na cultura digital "[...] o leitor não é mais reverente ao texto, concentrado e disciplinado, mas disperso, plano, navegador errante; não é mais receptor ou destinatário sem possibilidade de resposta, mas comenta, curte, redistribui, remixa". É como se houvesse uma espécie de "rompimento" da barreira que antes distinguia claramente a tríade autor, texto e leitor, pois nos parece que, na cibercultura, eles passaram a compartilhar esses papéis de forma híbrida, ou seja, sem uma delimitação severa.

É exatamente para esse perfil de aluno - que interage, se apropria, remixa e compartilha - apontado pela autora, que a educação literária aberta se mostra como uma opção ideal, pois é capaz de formar leitores críticos e autônomos, seja em sala de aula ou em outros espaços e tempos divergentes.

A análise dos dois portais REA - REliA e Apps Univesp - não esgota as inúmeras possibilidades que eles oferecem para enriquecer e auxiliar a educação literária aberta. Pelo contrário, serve apenas para termos uma ideia de como tratá-los como material didático pode modificar beneficamente a aprendizagem escolar (STAROBINAS, 2012).

\section{CONSIDERAÇÕES FINAIS}

O ensino de literatura no nível médio tem sido alvo de intensas discussões há um longo tempo. O motivo para tal debate é porque existe uma espécie de distanciamento entre a educação literária que é ofertada - pautada no estudo descontextualizado de escolas/períodos literários e puro biografismo - e alunos cada vez mais ligados às tecnologias e mídias digitais, para os quais uma abordagem anacrônica é bastante desestimulante. 
Em outras palavras, a literatura acaba sendo tratada dentro da escola como uma espécie de simulacro de si mesma, pois ao invés de os estudantes lerem as obras integralmente, recepcionando-as com plena autonomia, apenas aprendem sobre estilos de época, datas e a biografia de autores consagrados pelo cânone. Essa é, sem dúvida alguma, uma abordagem superficial, pois coloca a leitura do texto literário de lado em detrimento da aquisição de conhecimentos que não são tão essenciais à formação do leitor e que, provavelmente, serão utilizados unicamente em provas - para a obtenção de notas - e exames externos - vestibulares e o Enem - para o ingresso nas universidades.

Precisamos reconhecer que as tecnologias e as mídias digitais trouxeram novas configurações de leitura, de se consumir o texto literário. A literatura agora é apresentada por meio de diferentes linguagens e gêneros, tendo como suportes dispositivos eletrônicos. Sendo assim, devemos tirar proveito dessa intrínseca relação da literatura com a cultura digital e oportunizar aos alunos configurações de ensino e aprendizado mais arrojadas e flexíveis, permitindo que a leitura literária ocorra em quaisquer espaços e contextos nos quais eles se encontrem.

Tratando especificamente da BNCC, reconhecemos que a tentativa do campo artístico-literário em promover um "diálogo" com a cultura digital (que não deixa de ser válido e importante), o texto do documento enfatiza demais o trabalho com os gêneros e linguagens que servem de suporte para a literatura se manifestar, mas não coloca a leitura integral do texto no lugar de centralidade que lhe é devido no ensino de língua materna. Ou seja, não deixa em evidência que a fruição, o prazer e o confronto que ocorre mediante a leitura literária não é algo ultrapassado ou mera perfumaria, mas essencial à própria constituição humana.

Por sua vez, com o objetivo claro de apoiar a educação literária aberta, reconhecemos as potencialidades dos REA para alcançar esse propósito. Por serem recursos gratuitos e terem grande flexibilidade (podem ser usados, remixados e compartilhados livremente), possuem a capacidade de enriquecer as propostas didático-metodológicas de professores de literatura, considerando cenários digitais de aprendizagem.

Apesar de termos criticado enfaticamente o uso do livro didático, esclarecemos também que os REA por si só não podem dinamizar o ensino de literatura se o professor não mudar sua postura pedagógica. Para que a qualidade da educação literária ofertada aos estudantes seja garantida, o docente deve priorizar abordagens que propiciem a leitura 
integral dos textos que porventura irá trabalhar/ler com a turma e não apenas trazer a literatura de forma fragmentada, descontextualizada.

Basta apenas que estes profissionais encarem os REA como alternativas de aproximar o aluno da literatura, como uma nova maneira - autônoma e colaborativa - de se usar e produzir materiais didáticos mais dinâmicos e interessantes, capazes de cativar o público jovem.

\section{REFERÊNCIAS}

ALVES, J. H. P. O que ler? Por quê? A literatura e seu destino. In: DALVI, M. A.; REZENDE, N. L.; JOVER-FALEIROS, R. (Orgs.). Leitura de literatura na escola. São Paulo: Parábola, p. 35-49, 2013.

AMIEL, Tel. Educação aberta: configurando ambientes, práticas e recursos educacionais. In: SANTANA, B.; ROSSINI, C.; PRETTO, N. L. (Orgs.). Recursos Educacionais Abertos: práticas colaborativas e políticas públicas. - 1. ed., 1 imp. - Salvador: Edufba; São Paulo: Casa da Cultura Digital, 2012.

BRASIL. Base Nacional Comum Curricular: Ensino Médio. Brasília: MEC/Secretaria de Educação Básica, 2018.

BRASIL. Governo Federal. Machado de Assis. A Cartomante. Brasília, DF, 2021. Disponível em: http://www.dominiopublico.gov.br/download/texto/ua000181.pdf. Acesso em: 24 abr. 2021.

CASTELLS, Manuel. A sociedade em rede. São Paulo: Paz e Terra, 1999.

COLOMER, Teresa. Andar entre livros: a leitura literária na escola. Trad. Laura Sandroni. São Paulo: Global, 2007.

COSCARELLI, C. V.; CAFIERO, D. Ler e ensinar ler. In: COSCARELLI, C. V. (Org.). Leituras sobre a leitura: passos e espaços na sala de aula. Belo Horizonte: Vereda, 2013.

COSSON, Rildo. Letramento literário: teoria e prática. São Paulo: Contexto, 2006.

Círculos de leitura e letramento literário. São Paulo: Contexto, 2014.

Paradigmas do ensino da literatura. São Paulo: Contexto, 2020.

CURY, C. R. J. Direito à educação: direito à igualdade, direito à diferença. Cadernos de Pesquisa, São Paulo, n. 116, p. 245-262, 2002. 
DALVI, M. A. Literatura na escola: propostas didático-metodológicas. In: DALVI, M. A.; REZENDE, N. L.; JOVER-FALEIROS, R. (Orgs.). Leitura de literatura na escola. São Paulo: Parábola, p. 67-97, 2013.

DENZIN, Norman K.; LINCOLN, Yvonna S. (Orgs.). O planejamento da pesquisa qualitativa: teorias e abordagens. $2^{\mathrm{a}}$ edição. Porto Alegre: ArtMed, 2006.

FREIRE, Paulo. Pedagogia da autonomia: saberes necessários à prática educativa. 31 . ed. São Paulo: Paz e Terra, 2005.

GONSALES, P.; SEBRIAM, D. (Coord.). REliA - Recursos Educacionais com licenças Abertas. Disponível em: https://relia.org.br/. Acesso em: 04 mar. 2021.

GUILHEN, C. D. (Coord.). O foco narrativo. APPS UNIVESP - Repositório da Universidade Virtual de São Paulo. Disponível em:

https://apps.univesp.br/repositorio/foco-narrativo/. Acesso em: 04 mar. 2021.

IPIRANGA, Sarah. O papel da Literatura na BNCC: ensino, leitor, leitura e escola.

Revista de Letras, v. 1, n. 38, jan./jun. 2019. Disponível em:

http://www.periodicos.ufc.br/revletras/article/view/60020/161786. Acesso em: 20 jun. 2021.

JOBIM, J. L. A literatura no ensino médio: um modo de ver e usar. In: ZILBERMAN, R.; RÖSING, T. M. K. (Orgs.). Escola e leitura: velha crise, novas alternativas. São Paulo: Global, p. 113-136, 2009.

MARTINS, I. A literatura no ensino médio: quais os desafios do professor? In: BUNZEN, C.; MENDONÇA, M. (Org.). Português no ensino médio e formação do professor. São Paulo: Parábola, 2006.

. Ensino de literatura: interfaces com a cultura digital. Pensares em Revista, n. 5 , p. $62-82,2014$.

MORAN, J. M. Novas tecnologias e mediação pedagógica. Campinas: Papirus, 2000.

PRENSKY, Marc. Digital natives, digital immigrants. The Horizon, v. 9, n. 5, 2001.

ROJO, Roxane. Entre plataformas, ODAS e protótipos: novos multiletramentos em tempos de Web2. The ESPecialist: Descrição, Ensino e Aprendizagem, São Paulo, v. 38, n. 1, jan./jul. 2017. Disponível em: https://revistas.pucsp.br/esp/article/view/32219/23261. Acesso em: 30 abr. 2021.

ROUXEL, Annie. Aspectos metodológicos do ensino da literatura. In: DALVI, M. A.; REZENDE, N. L.; JOVER-FALEIROS, R. (Orgs.). Leitura de literatura na escola. São Paulo: Parábola, p.17-33, 2013.

RIBEIRO, Ana Elisa. Questões provisórias sobre literatura e tecnologia: um diálogo com Roger Chartier. Estudos de Literatura Brasileira Contemporânea, n. 47, v. 27, p. 97 118, jan./jun. 2016. 
SANTAELLA, Lucia. A aprendizagem ubíqua na educação aberta. Revista Tempos e Espaços em Educação, p. 15-22, 30 dez. 2014. Disponível em:

https://seer.ufs.br/index.php/revtee/article/viewFile/3446/3010. Acesso em: 23 fev. 2021.

STAROBINAS, Lilian. REA na educação básica: a colaboração como estratégia de enriquecimento dos processos de ensino-aprendizagem. In: SANTANA, B.; ROSSINI, C.; PRETTO, N. L. (Orgs.). Recursos Educacionais Abertos: práticas colaborativas e políticas públicas. - 1. ed., 1 imp. - Salvador: Edufba; São Paulo: Casa da Cultura Digital, 2012.

SILVA, E. L.; MENEZES, E. M. Metodologia da pesquisa e elaboração de dissertação. 3. ed. rev. atual. Florianópolis: Laboratório de Ensino a Distância da UFSC, 2001.

SILVA, M. C. A leitura literária com experiência. In: DALVI, M. A.; REZENDE, N. L.; JOVER-FALEIROS, R. (Orgs.). Leitura de literatura na escola. São Paulo: Parábola, p. 50-65, 2013.

TODOROV, Tzvetan. A literatura em perigo. Rio de Janeiro: DIFEL, 2009.

UNESCO. Commonwealth of Learning OER Policy Guidelines. 2011. Disponível em: http://unesdoc.unesco.org/images/0021/002136/213605e.pdf. Acesso em: 01 mar. 2021.

ZILBERMAN, Regina. O papel da literatura na escola. Via Atlântica, [S. l.], n. 14, p. 1122, 2008. DOI: 10.11606/va. v0i14.50376. Disponível em:

https://www.revistas.usp.br/viaatlantica/article/view/50376. Acesso em: 28 fev. 2021.

A escola e a leitura da literatura. In: ZILBERMAN, R.; RÖSING, T. M. K. (Orgs.). Escola e leitura: velha crise, novas alternativas. São Paulo: Global, p. 17-38, 2009.

Recebido em: 2021

Aprovado em: 2021

Publicado em: 2021 